\section{Total intravenous anaesthesia with propofol, alfentanil, and oxygen-air: three different dosage schemes}

Lucia van Leeuwen MD, Wouter W. A. Zuurmond MD, Louis Deen MD, Henk J. H. J. Helmers MD
Three different dosage schemes of propofol infusions combined with a fixed-rate alfentanil infusion were investigated in total intravenous anaesthesia. In 30 premedicated patients, divided at random into three groups, anaesthesia was induced with propofol $2 \mathrm{mg} \cdot \mathrm{kg}^{-1}$ immediately followed by an alfentanil infusion $10 \mu \mathrm{g} \cdot \mathrm{kg}^{-1} \cdot \mathrm{min}^{-1}$ as a loading dose which was decreased after ten minutes to a maintenance dose of $1 \mu \mathrm{g}$. $\mathrm{kg}^{-1} \cdot \mathrm{min}^{-1}$. Vecuronium bromide $0.1 \mathrm{mg} \cdot \mathrm{kg}^{-1}$ was used as the muscle relaxant. After induction of anaesthesia a propofol infusion $2 \mathrm{mg} \cdot \mathrm{kg}^{-1} \cdot \mathrm{hr}^{-1}$ was started in group $\mathrm{A}, 3 \mathrm{mg} \cdot \mathrm{kg}^{-1}$. $\mathrm{hr}^{-1}$ in group B and $4 \mathrm{mg} \cdot \mathrm{kg}^{-1} \mathrm{hr}^{-1}$ in group C. At signs of light anaesthesia supplementary bolus doses of $20 \mathrm{mg}$ propofol and $1 \mathrm{mg}$ alfentanil were given. The patients' lungs were ventilated with air-oxygen $\left(\mathrm{F}_{1} \mathrm{O}_{2}\right.$ 0.35). The mean systolic and diastolic blood pressures showed no statistical significant differences between the three groups. A significant $(P<0.01)$ decrease of the mean systolic and diastolic blood pressures was present after induction of anaesthesia and tracheal intubation. Recovery was uneventful in all but one patient, who had ventilatory depression that responded to naloxone $(0.2 \mathrm{mg} / \mathrm{V})$. Awareness did not occur in any patient. The only difference between the three groups was the higher number of supplementary bolus doses of propofol and alfentanil needed in group $A(P<0.01)$. In total intravenous anaesthesia propofol 3 and $4 \mathrm{mg} \cdot \mathrm{kg}^{-1} \cdot \mathrm{hr}^{-1}$ as a maintenance dose combined with a two-step fixed-rate alfentanil infusion provided smooth anaesthesia and uneventful rapid recovery.

\section{Key words}

ANAESTHETIC TECHNIQUES: intravenous, total; ANAESTHETICS, INTRA VENOUS: propofol; ANALGESICS: alfentanil.

From the Department of Anaesthesia, Academisch Medisch Centrum, Meibergdreef 9, 1105 AZ Amsterdam, The Netherlands.

Address correspondence to: Dr. L. van Leeuwen.
Trois différentes doses de perfusion du propofol combinées à un taux fixe d'alfentanil ont été investiguées lors d'une anesthésie intra-veineuse. Trente patients prémédiqués furent divisés au hasard en trois groupes et l'anesthésie fut induite avec du propofol $2 \mathrm{mg} \cdot \mathrm{kg}^{-1}$ immédiatement suivi de perfusion d'alfentanil de $10 \mu \mathrm{g} \cdot \mathrm{kg}^{-1} \cdot \mathrm{min}^{-1}$ pour une dose de charge qui fut plus tard diminuée après dix minutes à une dose de $I \mu \mathrm{g} \cdot \mathrm{kg}^{-1} \cdot \mathrm{min}^{-1}$, du bromure de vecuronium après l' induction de l'anesthésie une perfusion de propofol de $2 \mathrm{mg} \cdot \mathrm{kg}^{-1} \cdot \mathrm{hr}^{-1}$ fut commencée pour le groupe A, $3 \mathrm{mg} \cdot \mathrm{kg}^{-1} \cdot \mathrm{hr}^{-1}$ pour le groupe B et $4 \mathrm{mg} \cdot \mathrm{kg}^{-1}$. $h r^{-1}$ pour le groupe $C$. Aux signes d'une anesthésie légère des bolus supplémentaires de propofol $20 \mathrm{mg}$ et d'alfentanil $1 \mathrm{mg}$ furent administrés. Les patients furent ventillés avec de l'oxy. gène-air $\left(\mathrm{FlO}_{2} \mathrm{O}, 35\right)$. Les pressions moyennes systoliques et diastoliques n'ont pas démontré de différence statistiquement significative entre les trois groupes. Une diminution significative $(P<0,01)$ des pressions moyennes systoliques et diastoliques était observée après l'induction de l'anesthésie et l'intubation endotrachéale. Le réveil fut sans complication chez tous les patients sauf un qui a démontré une dépression respiratoire répondant au naloxone $(0,2 \mathrm{mg} \mathrm{IV})$. Aucun rappel n' est survenu chez ces patients. La seule différence entre les trois groupes fut le plus grand nombre de doses supplémentaires de propofol et $d$ 'alfentanil dans le groupe $A(P<0.01)$. Pour une anesthésie intra-veineuse du propofol $3 \mathrm{et} 4 \mathrm{mg} \cdot \mathrm{kg}^{-1} \cdot \mathrm{hr}^{-1}$ comme dose de maintien combiné à une perfusion à taux fixe d'alfentanil fournit une anesthésie sécuratire et un réveil rapide.

In the last few years much attention has been paid to the search for new techniques of total intravenous anaesthesia. These techniques would avoid the use of inhalational anaesthetics, including nitrous oxide, which might be harmful to patients, anaesthesists and other workers in an operating theatre. ${ }^{1,2}$

New shortacting hypnotics and analgesics are available with a wide therapeutic ratio which show little accumulation and which are suitable for continuous infusion. 
Propofol and alfentanil are both suitable to be given by infusion because their pharmacokinetic profiles predict little cumulative effects within therapeutic dosage ranges.

A fixed-rate alfentanil infusion for ten minutes of 10 $\mu \mathrm{g} \cdot \mathrm{kg}^{-1} \cdot \mathrm{min}^{-1}$ as a loading dose decreasing to $1 \mu \mathrm{g} \cdot$ $\mathrm{kg}^{-1} \cdot \mathrm{min}^{-1}$ during maintenance and combined with nitrous oxide-oxygen resulted in satisfactory anaesthesia and recovery in operations of medium and long duration. . $^{3,4}$ Using a continuous infusion of propofol, nitrous oxide can be replaced. However, the dosage scheme of propofol infusion combined with a fixed-rate alfentanil infusion is not known.

The present study was designed to evaluate propofol in three different dosage schemes for induction and maintenance of anaesthesia by continuous infusion, combined with a fixed-rate infusion of alfentanil.

\section{Methods}

Thirty ASA physical status class I and II patients, aged 15-72 years, weight $51-90 \mathrm{~kg}$, who were scheduled for orthopaedic or ophthalmic operations were studied. Verbal informed consent was obtained from all patients and the study was approved by the Medical Ethics Committee of the hospital. The patients were randomly allocated into three groups of ten patients each, Groups A, B, and C. All patients received premedication with diazepam $10 \mathrm{mg}$ orally one to one and a half hours before surgery. After pre-oxygenation, anaesthesia was induced in patients of Group A with propofol $2 \mathrm{mg} \cdot \mathrm{kg}^{-1}$. The hypnotic was given over $20 \mathrm{sec}$ into a fast-running infusion, immediately followed by a continuous alfentanil infusion at a fixed rate of $10 \mu \mathrm{g} \cdot \mathrm{kg}^{-1} \cdot \mathrm{min}^{-1}$, given by a modified Freseniusinjectomat infusion pump. A single dose of vecuronium bromide $0.1 \mathrm{mg} \cdot \mathrm{kg}^{-1}$ was used as the muscle relaxant. After tracheal intubation anaesthesia was maintained by a continuous infusion of propofol $2 \mathrm{mg} \cdot \mathrm{kg}^{-1} \cdot \mathrm{hr}^{-1}$. The alfentanil infusion was decreased after ten min to $1 \mu \mathrm{g}$. $\mathrm{kg}^{-1} \cdot \mathrm{min}^{-1}$. A supplementary bolus of propofol $20 \mathrm{mg}$ plus alfentanil $1 \mathrm{mg}$ was administered to suppress responses indicating light anaesthesia, defined as sweating, lacrimation, chewing on the tube, movement or a sudden increase of heart rate and/or systolic and diastolic blood pressures of more than 15 per cent of the baseline values. The lungs of all patients were ventilated with oxygen in air $\left(\mathrm{FIO}_{2} \mathrm{0.35}\right)$ to maintain end-expiratory $\mathrm{CO}_{2}$ between 4-5 vol per cent (measured by a calibrated capnograph). In Groups $B$ and $C$ the same protocol was followed, the only difference being the maintenance dose of propofol infusion which was given at a rate of 3 $\mathrm{mg} \cdot \mathrm{kg}^{-1} \cdot \mathrm{hr}^{-1}$ in Group B and $4 \mathrm{mg} \cdot \mathrm{kg}^{-1} \cdot \mathrm{hr}^{-1}$ Group C.

Using a non-invasive blood pressure monitor (Dinamap) and a continuous ECG, the heart rate, systolic and diastolic arterial blood pressure were recorded preopera- tively, as baseline values, before induction of anaesthesia, every minute (up to ten $\mathrm{min}$ ) following induction of anaesthesia and incision and at five min intervals until the end of the procedure.

The infusions of propofol and alfentanil were discontinued about ten minutes before the end of surgery. At the end of operation neuromuscular block was, when necessary, reversed with atropine and neostigmine. If respiratory depression was present, as evidenced by a respiratory rate of less than $10 \cdot \mathrm{min}^{-1}$ and a tidal volume of less than $350 \mathrm{ml}$, naloxone (0.2-0.4 mg) was injected IV. Recovery was measured as the time between stopping the infusions until the patients opened their eyes spontaneously and answered five questions (What is your name? How old are you? Show your right thumb. What day is it today? and How much is $7 \times 8$ ?). No other drugs were given before or during anaesthesia. All characteristics and side effects at induction, during maintenance and recovery, were noted. The total number of supplementary bolus doses of propofol and alfentanil during maintenance was recorded. The patients were questioned by the anaesthestist about intraoperative awareness. This was done in the recovery room, the day after and one month after the operation.

Statistical analysis was performed using the unpaired Student's $t$ test for the majority of group differences. Comparing the scores of the cardiovascular variables a repeated measures analysis of variance was performed followed by Student's t test for paired data. $P<0.05$ was considered to be significant.

\section{Results}

The three groups of patients were comparable with respect to mean age, weight and duration of anaesthesia (Table I). Induction of anaesthesia was rapid and smooth without hiccups or involuntary movement. Pain on injection of propofol was experienced by 12 out of 30 patients. The mean total doses (induction and maintenance) of both propofol and alfentanil administered to the patients in each group are listed in Table II.

Patients in Group A received more supplementary bolus doses of propofol and alfentanil during maintenance of anaesthesia than the other groups $(P<0.01)$. There was no significant difference between Groups B and C (Table III).

During the procedure mean systolic and diastolic blood pressures and heart rate showed similar patterns in the three groups. Repeated measures analysis of variance showed no group effects. The intergroup differences are shown in Figures 1,2 and 3. During maintenance of anaesthesia changes in blood pressure and heart rate were noticed in individual patients, varying with the depth of anaesthesia, but never exceeded 25 per cent of the 
TABLE I Age and weight of patients and duration of anaesthesia (mean \pm SD)

\begin{tabular}{llll}
\hline Groups & $A$ & $B$ & $C$ \\
\hline$n$ & 10 & 10 & 10 \\
Sex (F/M) & $4 / 6$ & $4 / 6$ & $7 / 3$ \\
Age (yr) & $27.1 \pm 10.9$ & $35.3 \pm 15.3$ & $34.7 \pm 9.5$ \\
& (range 15-49) & (range 21-72) & (range 24-44) \\
Weight (kg) & $67.8 \pm 9.6$ & $68.9 \pm 12.4$ & $74.8 \pm 11.4$ \\
& (range 51-85) & (range 51-85) & (range 52-90) \\
Duration of & $78.8 \pm 13.8$ & $72.8 \pm 27.7$ & $74.2 \pm 29.5$ \\
$\quad$ anaesthesia (min) & (range 62-105) & (range 46-138) & (range 40-125) \\
\hline
\end{tabular}

pre-anaesthetic values. No unacceptable hypotension or hypertension occurred in any patient and no treatment was necessary. However, in five patients atropine $0.5 \mathrm{mg}$ was given IV when bradycardia, heart rate $<50 \cdot \mathrm{min}^{-1}$, occurred. Recovery showed no significant differences among the three groups (Table IV).

Ventilatory depression occurred in only one patient in Group $\mathrm{C}$ who responded well to naloxone $0.2 \mathrm{mg}$ IV. The incidences of side effects at induction, during maintenance and postoperatively are listed in Table V. Awareness did not occur in any patient. All patients reported total amnesia for the intraoperative period and were satisfied with this kind of anaesthesia.

\section{Discussion}

This study on total intravenous anaesthesia compared three different dosage regimens of continuous propofol infusions of 2,3 and $4 \mathrm{mg} \cdot \mathrm{kg}^{-1} \cdot \mathrm{hr}^{-1}$ combined with a fixed-rate alfentanil infusion of $10 \mu \mathrm{g} \cdot \mathrm{kg}^{-1} \cdot \mathrm{min}^{-1}$ for

TABLE II Mean total dosage propofol and alfentanil (induction and maintenance) (mean \pm SD)

\begin{tabular}{lll}
\hline & Propofol $m g$ & Alfentanil $m g$ \\
\hline Group A & $391.8 \pm 57.7^{*}$ & $15.4 \pm 2.5^{*}$ \\
Group B & $412.7 \pm 147.2$ & $11.9 \pm 3.3^{*}$ \\
Group C & $528.0 \pm 180.2^{*}$ & $12.5 \pm 3.3$ \\
\hline
\end{tabular}

$* P<0.05$.

TABLE IIl Number of patients requiring supplementary bolus doses

\begin{tabular}{|c|c|c|c|c|c|c|c|c|}
\hline Zero & One & Two & Three & Four & Five & Six & Seven & Totc \\
\hline 0 & 1 & 2 & 2 & 1 & 1 & 1 & 2 & 40 \\
\hline 5 & 3 & 1 & 1 & 0 & 0 & 0 & 0 & 8 \\
\hline 8 & 2 & 0 & 0 & 0 & 0 & 0 & 0 & 2 \\
\hline
\end{tabular}

TABLE IV Mean values $\pm S D$ of recovery

\begin{tabular}{lccc}
\hline & Group A & Group B & Group C \\
\hline $\begin{array}{l}\text { Time to eye opening (min) } \\
\text { Time to giving correct answers } \\
\text { to 5 questions (min) }\end{array}$ & $14.5 \pm 3.2$ & $13.0 \pm 3.2$ & $14.5 \pm 4.7$ \\
\hline
\end{tabular}

ten minutes as a loading dose, decreasing to $1 \mu \mathrm{g} \cdot \mathrm{kg}^{-1}$. $\mathrm{min}^{-1}$ during maintenance of anaesthesia. The only difference among the three groups was the number of supplementary doses of propofol $(20 \mathrm{mg})$ and alfentanil $(1 \mathrm{mg})$. However, the awakening time was not influenced.

The $2 \mathrm{mg} \cdot \mathrm{kg}^{-1} \cdot \mathrm{hr}^{-1}$ dosage scheme of propofol was obviously too low: all patients needed one or more extra doses, which was more than in the other groups $(P<$ 0.01 ). Although the patients reported no awareness during the intraoperative period when questioned, the reason for the supplementary bolus doses was light anaesthesia defined as sweating, lacrimation, chewing on the tube, movement or a sudden increase of heart rate or systolic and diastolic blood pressure of more than 15 per cent of baseline values. In our study, we preferred a continuous infusion to the titration of bolus injections to prevent the peak and trough effects of light anaesthesia.

TABLE V Incidence of side-effects and postoperative drug administration

\begin{tabular}{llll}
\hline & \multicolumn{3}{l}{ Group } \\
\cline { 2 - 4 } & $A$ & $B$ & $C$ \\
\hline Pain of injection & 4 & 5 & 3 \\
Neostigmine (1 mg), atropine (0.5 mg) IV & 1 & 2 & 2 \\
Naloxone (0.2 mg) IV & 0 & 0 & 1 \\
Nausea & 2 & 1 & 1 \\
Vomiting & 0 & 0 & 1 \\
Antiemetic drug given & 2 & 1 & 1 \\
Dizziness, headache & 0 & 1 & 1 \\
Euphoria & 3 & 2 & 2 \\
Awareness & 0 & 0 & 0 \\
\hline
\end{tabular}


Systolic arterial pressure (mean + SD)

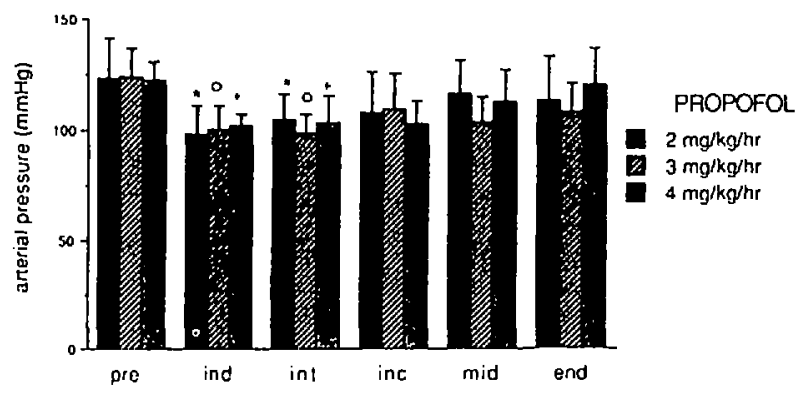

FIGURE 1 Mean values for systolic arterial pressure at bascline preinduction values (pre), after induction (ind), after intubation (int), after incision (inc), middle of operation (mid), end of operation (end). $* P<0.01, O P<0.01,+P<0.01$.

Diastolic arterial pressure (mean + SD)

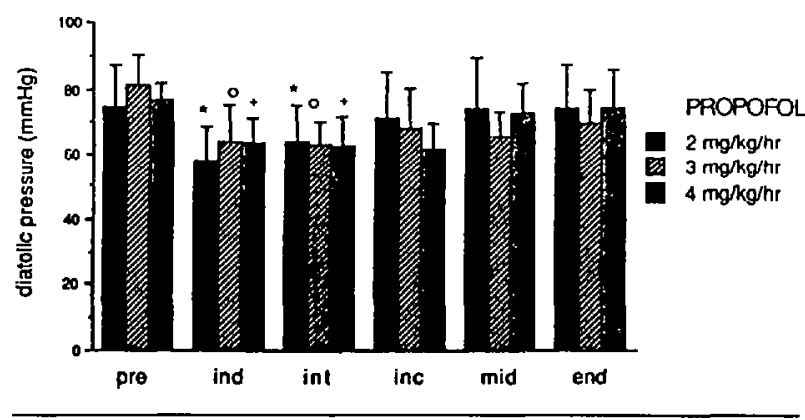

FIGURE 2 Mean values for diastolic arterial pressure at bascline pre-induction values (pre), after induction (ind), after intubation (int), after incision (inc), middle of operation (mid), end of operation (end). ${ }^{*} P<0.01, \bigcirc P<0.01,+P<0.01$.

Moreover, the mean total dose of propofol for induction and maintenance including the supplementary doses did not differ significantly between Groups $A$ and $B$, while more supplementary bolus doses were needed in Group A than in Group B, being respectively 40 and $8(P<0.01)$. Nevertheless, the mean total alfentanil dose in Group $A$ was significantly greater than in Group B $(P<0.05)$. When a supplementary bolus dose was needed by signs of light anaesthesia, we administered both propofol and alfentanil together because it is difficult to determine whether pain or awakening is the cause of the light anaesthesia.

In previous studies a fixed-rate alfentanil infusion of 10 $\mu \mathrm{g} \cdot \mathrm{kg}^{-1} \cdot \mathrm{min}^{-1}$ for ten minutes as a loading dose decreasing to $1 \mu \mathrm{g} \cdot \mathrm{kg}^{-1} \cdot \mathrm{min}^{-1}$ during maintenance combined with nitrous oxide-oxygen resulted in satisfactory anaesthesia and recovery in operations of medium and

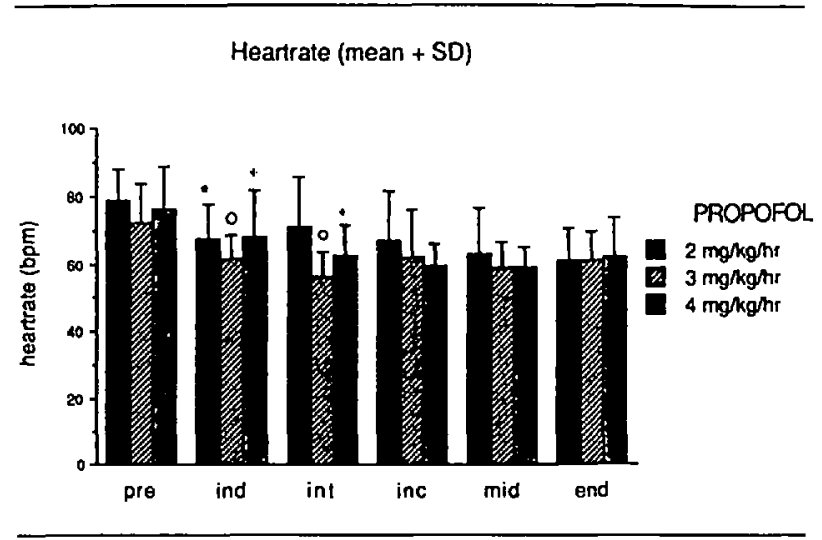

FIGURE 3 Mcan values for heart rate at baseline pre-induction values (pre), after induction (ind), after intubation (int), after incision (inc), middle of operation (mid), end of operation (end). ${ }^{*} P<0.01$, $O P<0.01,+P<0.01$.

long duration. ${ }^{3,4}$ We used propofol instead of nitrous oxide to avoid inhalational anaesthetics. Propofol, in contrast to nitrous oxide, has no analgesic properties, and was the reason why we kept the infusion regimen of alfentanil at the above-mentioned fixed-rate. Because propofol and alfentanil seem to potentiate each other, ${ }^{5}$ we evaluated lower propofol infusion rates than recommended by other investigators; ${ }^{2,6-9}$ moreover, the stepped propofol scheme, a loading dose of $1 \mathrm{mg} \cdot \mathrm{kg}^{-1}$ followed by three stepped infusions at $10 \mathrm{mg} \cdot \mathrm{kg}^{-1} \cdot \mathrm{hr}^{-1}$ for ten minutes, $8 \mathrm{mg} \cdot \mathrm{kg}^{-1} \cdot \mathrm{hr}^{-1}$ for a further ten minutes and then $6 \mathrm{mg} \cdot \mathrm{kg}^{-1} \cdot \mathrm{hr}^{-1}$ for the remainder of the infusion 9 combined with the two-step fixed-rate alfentanil infusion does not simplify the ease of administration of total intravenous anaesthesia.

The incidence of pain on injection during induction of anaesthesia in our study (40 per cent) was not different from that reported by other investigators. ${ }^{8,10}$ This can be decreased by injecting propofol into the large veins of the forearm or antecubital foss $a^{10}$ and by starting the infusion of alfentanil before the injection of propofol. Administering the fixed-rate continuous alfentanil infusion, combined with nitrous oxide, resulted in nausea and vomiting in 15-24 per cent of the patients. ${ }^{4,5}$ In this study we found an incidence of 13 per cent.

In conclusion total intravenous anaesthesia with propofol 3 and $4 \mathrm{~m} \cdot \mathrm{kg}^{-1} \cdot \mathrm{hr}^{-1}$ combined with a fixed-rate alfentanil infusion of $10 \mu \mathrm{g} \cdot \mathrm{kg}^{-1} \cdot \mathrm{min}^{-1}$ for ten minutes decreasing to $1 \mu \mathrm{g} \cdot \mathrm{kg}^{-1} \cdot \mathrm{min}^{-1}$ provided satisfactory anaesthesia for operations of medium and long duration with a rapid recovery. 


\section{References}

1 Simmons $K$. Some sobering facts about laughing gas. JAMA 1985; 253: 2334-7.

2 Steegers PA, Foster PA. Propofol in total intravenous anaesthesia without nitrous-oxide. Anaesthesia 1988; 43 (suppl): 94-7.

3 van Leeuwen L, Zuurmond WWA, Helmers JHJH, Noorduin $H$, Deen $L$. Alfentanil-dauerinfusion für chirurgische Eingriffe mittleren und längeren Dauer. Anacsthesist 1984; 33: 173-6.

4 Zuurmond WWA, van Leeuwen L. Fixed-rate alfentanil infusions for surgery of variable duration. Eur J Anaesth 1987; 4 (suppl 1): 35-8.

5 Gepts E, Jonckheer $K$, Maes V, Sonet W, Camu F. Disposition kinetics of propofol during alfentanil anaesthesia. Anaesthesia 1988; 43 (suppl): 8-13.

6 Schüttler J, Kloos $S$, Schwilden $H$. Total intravenous anaesthesia with propofol and alfentanil by computer assisted infusion. Anaesthesia 1988; 43 (suppl): 1-7.

7 Kay $B$. Propofol and alfentanil infusions. Anaesthesia 1986; 41: 589-95.

8 de Grood PMRM, Harbers JBM, van Egmond J, Crul $J F$. Anaesthesia for laparoscopy. Anaesthesia 1987; 42: 815-23.

9 Roberts FL, Dixon J, Lewis GTR, Tackley RM, PrysRoberts $E$. Induction and maintenance of propofol infusion. Anaesthesia 1988; 43 (suppl): 14-7.

$10 \mathrm{McC}$ Collum JSC, Dundee JW. Comparison of induction characteristics of four intravenous anaesthetic agents. Anaesthesia 1986; 41: 995-1000. 